\title{
Mapping the field of military nursing research 1990-2013: A bibliometric review
}

\author{
Jane Currie and Jennifer Chipps
}

\begin{abstract}
Background: Over the past 20 years, military forces worldwide have been engaged in a number of conflicts and humanitarian operations and the impact of this on the field of military nursing research is unknown. The aim of this bibliometric review was to investigate the research field of military nursing in the main databases with the purpose to describe trends in military nursing research since 1990.

Objectives: To identify military nursing papers in the main databases and to describe the field of military nursing research for the period 1990-2013 in terms of research productivity, trends in topic focus, trends in authorship and country of publication.

Method: Bibliometric review of published military nursing research papers was undertaken in March 2014 and data was extracted and coded and trends were analyzed using SPSSv21. Results: In total 237 articles were included in the review. The majority of publications emanating from America $(n=175,73.8 \%)$ and the quantity of papers has increased significantly since the commencement of the second Gulf War in Iraq from 2003 onwards ( $n=156,65.8 \%$ ). This has been accompanied by a shift in topic focus from professional ( $n=16,20.3 \%)$ and occupational issues $(n=17,21.5 \%)$ pre 2003 , to clinical $(n=48$, $30.4 \%$ ) and an increase in multidisciplinary research from $4 \%$ in $1990-94$ to $29 \%$ in $2010-$ 13. The mean citations were 10.6 (sd 17.0) and the mean references per paper post 2003 showed a marked increase from 23.5 to 25.4 .

Conclusion: The military nursing research field appears stronger than it has been in the past twenty years and has demonstrated increased transferability to other fields. To maintain this momentum and further develop the field of military nursing research, military forces worldwide need to devise focused nursing research strategies that involve international and multidisciplinary collaboration.
\end{abstract}

\section{What is already known about the topic?}

1. Conflicts in Iraq and Afghanistan have led to significant advances in health care practices.

2. Military nursing research has the potential to forward both military and civilian nursing practice.

\section{What this paper adds}

1. The military nursing research field appears underdeveloped, although there are signs of increased momentum in terms of the quantity of papers published, the number of 
references per paper, the impact factor of journals and the increase in multidisciplinary research, which holds potential for the transferability of military nursing knowledge to other fields.

2. To further develop the military nursing research field, military nursing forces need to devise research strategies that include international and multidisciplinary collaboration.

\section{Background}

Military nursing research is an important field because the lessons learned by military nursing during recent world events has the potential to forward both military and civilian nursing practice, particularly in specialist areas such as trauma, mental health, public health and surgical nursing. Yet, little is known about the international field of military nursing research, in terms of publication trends, topic focus and collaboration. This paper addresses this through a bibliometric process that will review and describe trends in the published peer reviewed research in the field of military nursing. For the purpose of this review the term 'military nursing research' refers to peer reviewed research that focuses on military nursing as the major topic and/or holds recommendations for the practice of military nursing.

The Army Nursing Service was established in the United Kingdom (UK) in 1881 and this was the first formal organization of military nursing. The Army Nursing Service was an organization that oversaw the work of military nurses deploying them overseas, beginning with the First Boer War. Military nursing was the birthplace of a number of significant health care practices, many of which were translated into civilian practice. Most notable for nursing were those instigated by Florence Nightingale during the Crimean War and documented in 'Notes on Nursing' and included practices related to infection control and patient nutrition (Nightingale, 1859). Many advances in care and treatment have and will continue to be made as a result of the health care and treatment provided to casualties of war, conflict and humanitarian disasters and it is important that these are documented (Feider et al., 2012).

More recently, conflicts in Iraq and Afghanistan have led to significant advances in health care practices, in particular damage control surgery, damage control resuscitation, massive transfusion protocols, infection control and trauma reporting systems (Aronson et al., 2006; Eastridge et al., 2006; Hodgetts et al., 2007; Wildridge et al., 2012). A citation analysis of combat casualty research identified advances in the management of massive haemorrhage as the most significant contribution to military health care and that lessons learned have been adopted into civilian trauma paradigms (Orman et al., 2012).

The conflicts in the Middle East have exposed military nurses to patterns of injury rarely experienced in civilian health care and this has presented an opportunity to further evolve military nursing knowledge and practice. The injury patterns from ballistic trauma present challenges for all specialties of nursing involved in the patients' care, particularly as a large proportion of patients, up to 69\%, injured in the second Gulf War (2003-2011) and/or Afghanistan (2001-2014) suffered polytrauma (Bridges, 2010, p. S75). Providing care for injured patients in military operational environments requires military nurses to take consideration of constraints in resources, such as equipment, time and environmental conditions and this often requires nurses to adapt their approach to 
care to suit a particular situation in order to optimize health outcomes. The long-term rehabilitation of injured military personnel, both physical and psychological, also presents unique challenges for military nursing, the wider health care system and Veterans health.

However, it has been argued that there is limited research evidence underpinning military nursing practice (Bridges, 2010). The advances in military nursing knowledge provide potential opportunities for translation into most civilian fields of nursing, particularly trauma, critical care, perioperative and mental health nursing. The translation of combat casualty research, such as trauma governance and treatment of massive haemorrhage are evidence of the utility of military research to the civilian setting (Hettiaratchy et al., 2010; Orman et al., 2012). Capturing the lessons learned and ensuring that military nursing builds upon a firm evidence base is essential and will facilitate ongoing advancement of care paradigms as well as translation of practices into the civilian setting. The impact of military conflicts and humanitarian operations on the field of military nursing research is currently unknown and to investigate this the authors undertook a bibliometric review. The review is designed to investigate the field of military nursing research papers published in the main databases between 1990 and 2013, to describe the field in terms of research productivity, trends in topic focus, trends in authorship and country of publication to gain a sense of the development of the military nursing field.

\section{Method}

\subsection{Review strategy: bibliometrics}

Bibliometrics provides a quantitative analysis of the literature published within a specific field and provides a method of mapping the development and structure of a given scientific field (Clarke et al., 2007; Estabrooks et al., 2004; Lievrouw, 1989). The intention of a bibliometric review is to map the published research within a particular field so that commonalities and differences can be exposed which may include, the most common research topics and trends within a field, the core authors, patterns of collaboration, assessing research in terms of output funding, impact and geographic trends (Anderson et al., 2009). A key assumption of bibliometrics is that the publications reflect the knowledge base within that field (Estabrooks et al., 2004).

For the purpose of this study, the focus was on military nursing research papers between 1990 and 2013 published in peer-reviewed academic journals in the main health databases. This time period includes a number of conflicts involving multinational forces including the first (1990- 1991) and second Gulf Wars, Sierra Leone Civil War (19912002), War in Afghanistan and East Timorese Crisis, from which a number of military research based health care innovations resulted. By choosing the period 1990-2013, the authors were able to identify trends in research productivity, trends in topic focus, trends in authorship and country of publication.

\subsection{Literature search}

Military nursing research papers were defined as research papers where military nursing were the major topic or where the recommendations were for military nursing in the main health databases. To confirm the choice of relevant major subject headings or MeSH terms, a search of Google Scholar, Medline and 
CINAHL was conducted. The final search terms selected included: Military or Army or Navy, Air Force or Veteran or Defence and nursing. A systematic search of the published literature was undertaken using the following databases: Pubmed, CINAHL, Psychinfo, Psycharticles, Academic Search Complete (database that includes all health databases).

\subsection{Inclusion and exclusion criteria}

All languages were included in the search and papers were included if the content focused on military nursing where military nursing was identified as the major topic and or, if the content held recommendations for military nursing. Papers were excluded if the content held no recommendations for military nursing or focus on military nursing. Non-research papers were excluded such as letters, editorials, news reports, conferences and obituaries.

\subsection{Data extraction}

The initial search of all articles $(n=2693)$ was saved to Refworks and any duplicate articles were removed ( $n=459$ duplicates). The search process is outlined by Fig. 1. Working together, the authors screened the title and abstracts against the inclusion criteria. Papers with no focus on military nursing and no recommendations for military nursing practice were excluded using the exclusion criteria $(n=600)$. A number of papers were excluded because they were not research papers and instead provided an anecdotal account of experiences in military environments $(n=1411)$. A number of articles in a special military nursing edition of the Journal of Nursing Research were identified from the reference lists of the included papers. The special edition was investigated and the articles not already identified in the search were included $(n=14)$.

Full articles were retrieved where possible and reviewed by the two authors. The key challenge of data extraction was deciding whether the focus of the paper was upon military nursing or whether the paper held recommendations for military nursing. For the large proportion of papers that were reviewed, the focus was clear to both authors. Where there were initial disagreements, these were resolved by referring to and adhering to the coding criteria. For example, a research paper by a military nurse author on hospital units in the US (Patrician, 2013) was excluded as it had no direct relevance to military nursing. As an example of the type of papers that were included, Leon et al. (1990) undertook a quantitative study exploring the coping patterns of nurses who deployed to Vietnam and because this was directly focused upon military nursing it was included. Similarly, papers focused upon military nursing practice, such as the practice challenges facing army nurses in humanitarian and wartime missions (Agazio, 2010) was included. 


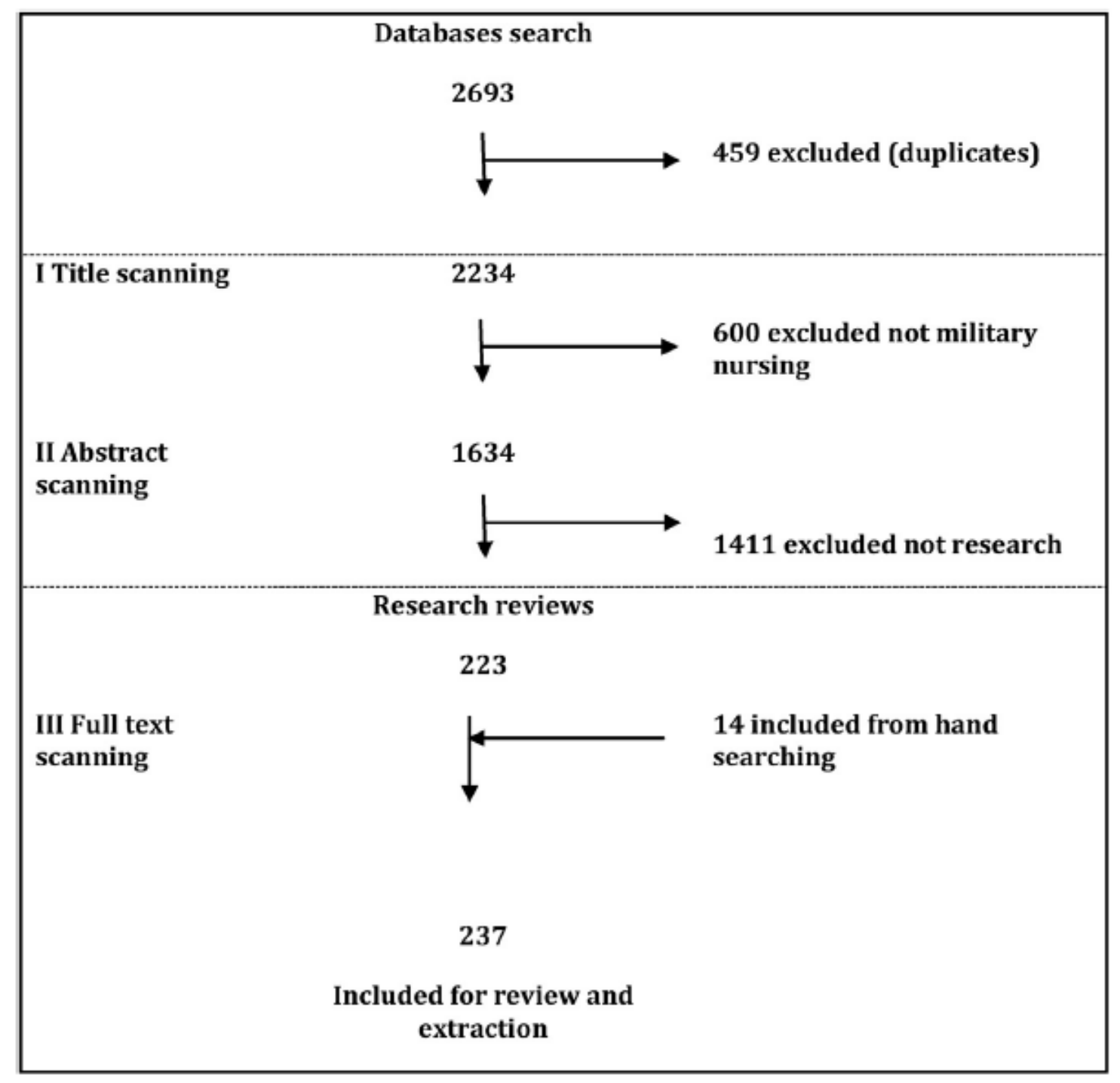

Fig. 1. Search and retrieval flow diagram.

\subsection{Data coding}

Data from primary research articles were then extracted and coded using a coding sheet with criteria which were developed by the authors for (1) author name and whether (2) military or non military, (3) year, (4) journal, (5) country of publication, (6) language of paper, (7) type of research (quantitative, qualitative, mixed, evaluation and historical), (8) main focus, (9) military nursing or recommendations for military nursing, (10) content area of paper, and (11) operational nature. Operational nature was defined as the operation upon which the research was focused and coded by the name of the conflict. In the case of humanitarian aid missions papers were coded as humanitarian and then by the country the mission occurred in. The category 'deployed' referred to research that focused on military personnel working overseas on an established base, for example UK military stationed in Cyprus. The authors' military status was coded as either 'military' 'non-military' or 'unknown'. Military authors were identified by military rank. Where it was not clear whether the author was a member of the military (either retired or currently serving) the authors name was searched via Google to clarify. Evidence of the research process was rated using a scale from 1 (Research process headings and detailed research methodology description); 2 (Research process headings but 
inadequate research methodology descriptions); and 3 (No research process headings and inadequate research methodology descriptions). The authors devised this rating scale and, whilst subjective it does offer some indication to the rigour of the findings of each research paper. The multidisciplinary nature of the research was assessed by determining whether the paper focused on nursing only or whether the authorship was multidisciplinary including professional groups outside of nursing, such as medicine, paramedicine and/or physiotherapy. For example, papers focusing on Critical Care Air Transport Teams were identified as multidisciplinary because the research involved members of the multidisciplinary team, in this case nurses and doctors (Lairet et al., 2013).

Citation data were accessed from citation counts using Google Scholar and reference lists were manually extracted. Where available the most recent impact factors for journals were accessed via the journal's home page. Data were then exported to SPSS v21.o for analysis and the following publication counts analysis were conducted: country and journal analysis, citation, reference and impact factors. In addition, publication counts were analyzed for focus of research and subject domain. Differences in the time period, prior to and after the commencement of the Gulf War (pre 2003) were analyzed for various bibliometric measures using Chi-squared tests (Fisher Exact where appropriate) and non-parametric Mann-Whitney $U$ tests for independent samples where appropriate. This analysis was undertaken following the initial analysis of the papers because trends emerged as to the increase in clinical focus of research topic and an increase in quantity of papers post 2003. In addition, trends were also analyzed for five year periods to smooth out random yearly variations. Author analysis was conducted in Excel and the top authors were checked in Scopus for co-authorships, affiliation and standing (Using hindex and citations by papers). The $\mathrm{h}$-index is a rating scale for the performance of academics and is calculated through the number of publications and the number of citations of an author (Thompson and Watson, 2010).

\section{Results}

A total of 237 papers (14\%) met the selection inclusion criteria. Of the total number of papers, 200 (84.4\%) full papers were retrieved, and 37 had abstracts only. Most of the papers were written in English $(n=214,90.3 \%)$ and for the foreign papers, the abstracts were in English. The number of publications by year demonstrated a marked increase over the past decade and the increase over the period 1990-2013 is particularly clear when presented as five-year trends (Figs. 2 and 3).

\subsection{Country analysis}

The majority of the publications emanated from the United States of America (US) ( $n=$ 175, 73.8\%), second highest from Brazil $(n=16,6.8 \%)$ followed by the UK ( $n=14$, $5.9 \%$ ) and Australia $(n=9,3.8 \%)$. When analyzing this by 5 year trend, the US has maintained a consistent publication increase since 1990, where both Brazil and the UK, published primarily from 2005 onwards and nearly 50\% $(n=4)$ of Australia's papers were published from 2000 to 2005. The trends of publication counts in the US, Australia and the UK were influenced by the military activity of the countries at that time. All of the papers that focused on the Gulf Wars and War in Afghanistan (2001- 2014) were published by the US (except one paper by the UK), 8 of Australia's 9 papers were on the 
Malay and Vietnam wars and 12 of the 16 Brazilian papers were on the Second World War Detailed metrics on country, author and type of research are presented in Table 1.

\subsection{Journal analysis}

The papers were published in 100 journals of which 15 were non-nursing journals. Military Medicine (impact factor 0.77) was the most popular journal ( $n=53,22.4 \%$ ) followed by Nursing Research (impact factor 1.6, $n=11,4.6 \%$ ). The most current journal impact factors were only found for 19 journals (mean 1.7 and median 0.8 , range 0-6.2). The top 7 impact factors were for medical journals, meaning journals from the discipline of medical science, with the highest being 6.2 for Critical Care Medicine. None of the nursing journals had an impact factor above 2 in contrast with 7 medical journals (8 papers) that did. In further analysis of the impact of journals and papers on the field, a citation analysis and a paper reference analysis were done. Citations of papers in Google scholar in July $2014(n=212)$ ranged from o to 133 per paper with a mean of 10.6 ( $\mathrm{sd}$ 17.0) citations per paper and a median of 5 citations per paper. One paper was excluded from this analysis as it was identified as an outlier with 388 citations (Mabry et al., 2000). References per paper ranged from o to 82, with a mean of 23.5 references per paper (sd 1.0) and a median of 21 references per paper. In comparing the references per article from pre-second Gulf War (19.8 sd 1.6) to the references post commencement of the second Gulf War (25.4 sd 1.3), a significant increase in references per paper were noted $(U=2.8, p=.005)$.

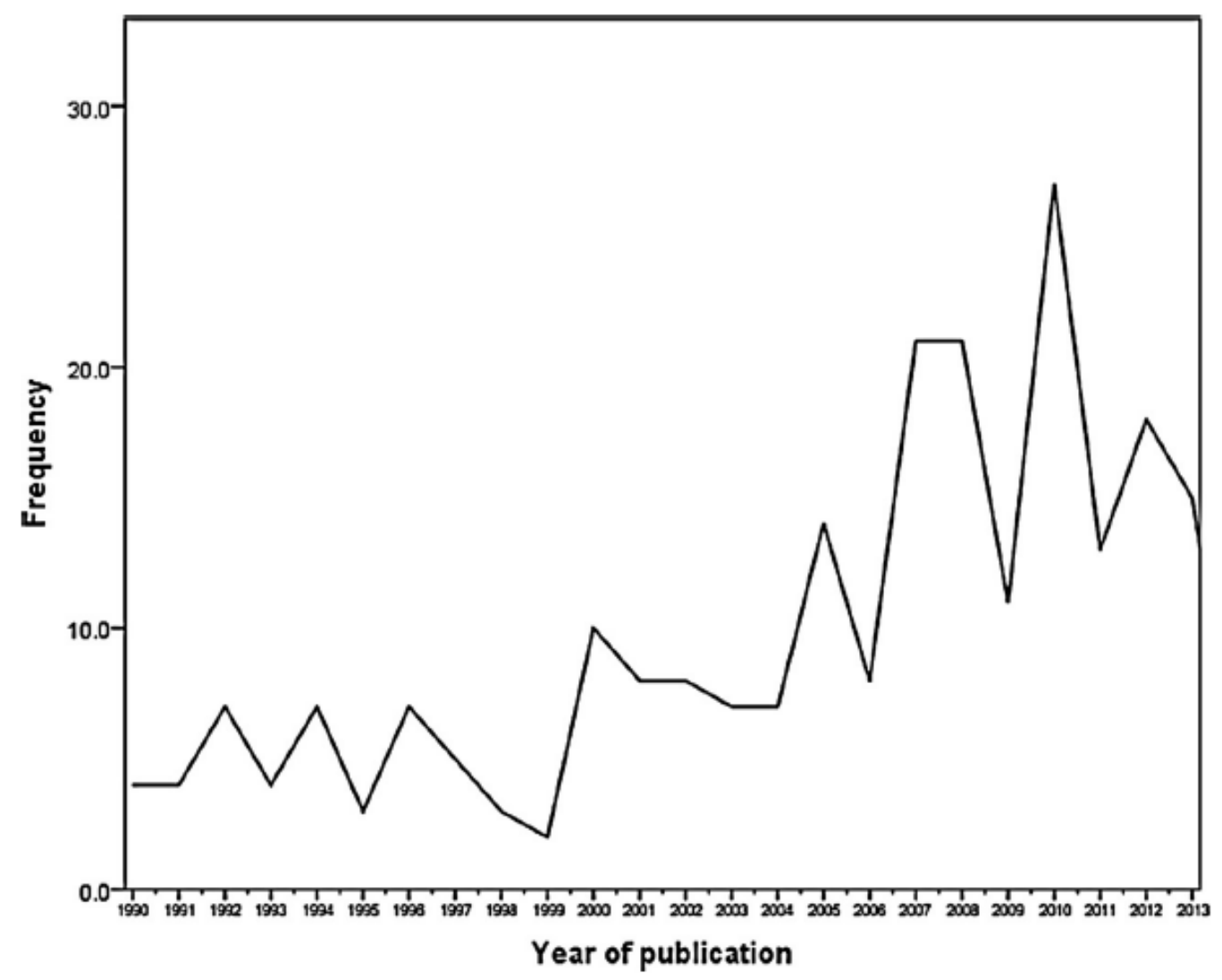

Fig. 2. Publication counts per year. 


\subsection{Author analysis}

The authors with the highest quantity of military nursing research publications are shown in Table 2. In the top 5 authors, three authors, Santos, T.C.F, Lopes, G.T. and Bernandes M.M. were collaborators from the same university in Brazil. They published a series of social-historical studies on the Brazilian army nurse in the Second World War. The most prolific authors in the US were Patrician, P.A. and Loan, L.A who published articles from a non-operational perspective focusing on education and management; and also from the US, Kenny, D.J. $(n=7)$. Patrician was also the most prolific author of all types of articles in Scopus. The h-indices of the top authors ranged from 3 to 8 with the US authors having the highest h-indices.

Two other aspects of authorship were analyzed, identification of military rank by authors and the trends in multidisciplinary research in military nursing. Military personnel identified themselves as such in 50.2\% (119) of the papers, 79 (33.3\%) authors were not military personnel. In looking at the trends of multidisciplinary research in five year periods, there is a significant trend of increasing multidisciplinary collaboration, ranging from $4 \%$ in $1990-1994$ to $29 \%$ in $2010-2014\left(X^{2}=12.2, p=.013\right.$ ) (Fig. 4).

\subsection{Focus and subject domain analysis}

Focus and subject domain were analyzed in two ways, firstly whether the main focus was military nursing or recommendations relevant for military nursing and secondly what the main subject domain was.

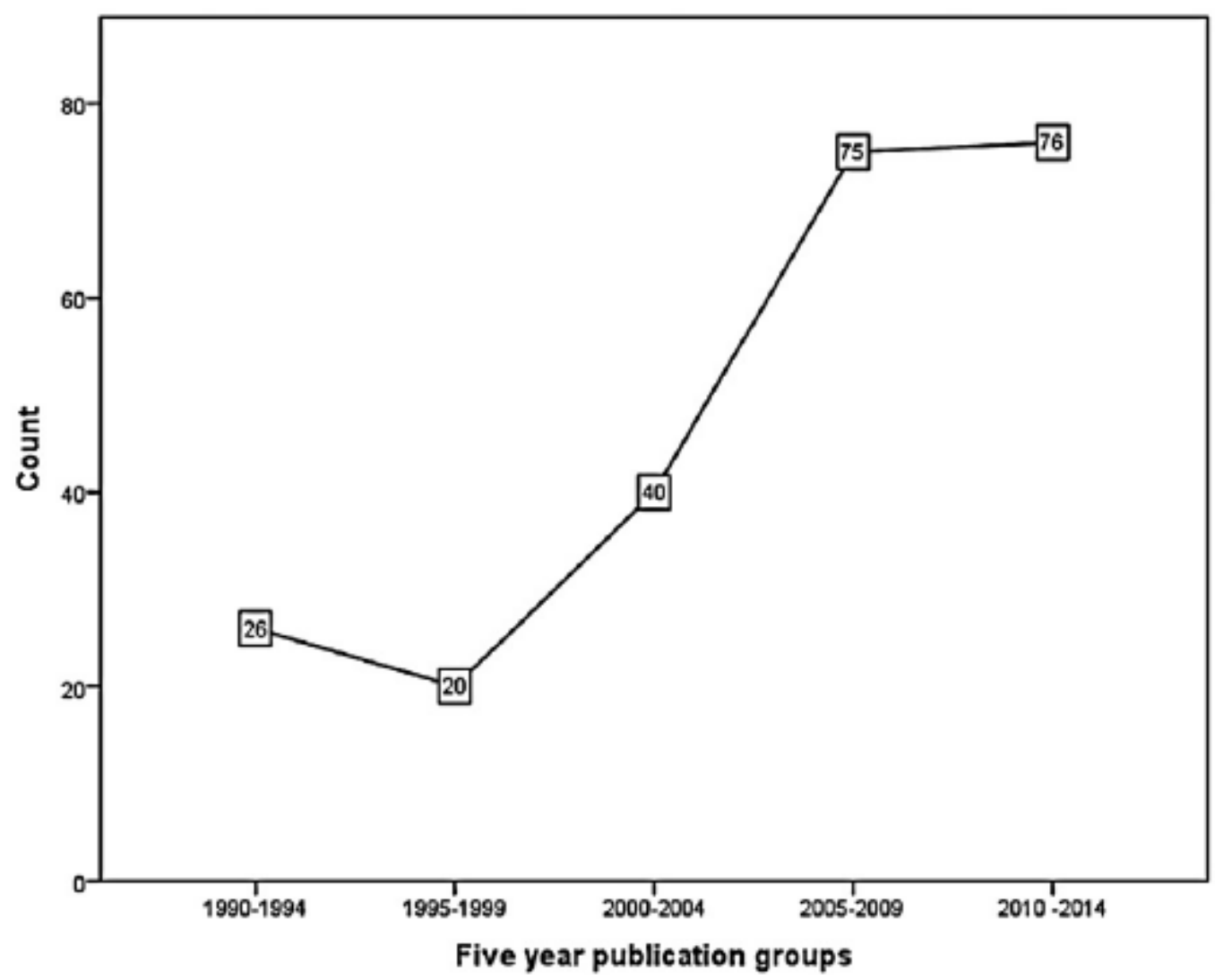

Fig. 3. Five year publication groups. (The five year groups extend to the 1 st January 2014 to ensure inclusion of the full study period 1990-2013.) 
Table 1

Summary characteristics of research (Where the values in the columns do not add up to 237, this is because the authors have highlighted the most prolific items. For example, only the top four countries of publication have been highlighted).

\begin{tabular}{|c|c|c|c|c|c|}
\hline Characteristic $n=237$ & $\begin{array}{l}N=237 \\
n(\%)\end{array}$ & $\begin{array}{l}\text { Post onset of second Gulf War }(>=2003) \\
n=156\end{array}$ & $\begin{array}{l}\text { Pre-second Gulf War }(<2003) \\
n=79\end{array}$ & Test $X^{2}$ & $P$-Value \\
\hline Country of publication & & & & 28.4 & $.025^{\circ}$ \\
\hline USA & $175(73.8 \%)$ & 107 (67.7\%) & $68(96.2 \%)$ & & \\
\hline Brazil & $16(6.8 \%)$ & $16(10.1 \%)$ & 0 & & \\
\hline UK & $14(5.9 \%)$ & $13(8.2 \%)$ & $1(1.3 \%)$ & & \\
\hline Australia & $9(3.8 \%)$ & $4(2.5 \%)$ & $5(6.3 \%)$ & & \\
\hline Type of journal & & & & 6.1 & $.027^{\circ}$ \\
\hline Nursing & $156(65.8 \%)$ & $112(70.9 \%)$ & $44(55.7 \%)$ & & \\
\hline Medical/Multi & $81(34.2 \%)$ & $46(29.1 \%)$ & $35(44.3 \%)$ & & \\
\hline Military Medicine & 53 (22.4\%) & $26(16.5 \%)$ & 27 (34.2\%) & & \\
\hline Nursing Research & $11(4.6 \%)$ & $9(5.7 \%)$ & $2(2.5 \%)$ & & \\
\hline Journal of Advanced Nursing & $9(3.8 \%)$ & $5(3.2 \%)$ & $4(5.1 \%)$ & & \\
\hline British Journal of Nursing & $6(2.5 \%)$ & $5(3.2 \%)$ & $1(1.3 \%)$ & & \\
\hline Communicating Nurs Res & $6(2.5 \%)$ & $6(3.8 \%)$ & 0 & & \\
\hline Type of military activity & & & & 38.1 & $.002^{\circ}$ \\
\hline Non-operational & $119(50.2 \%)$ & $79(50 \%)$ & $40(50.6 \%)$ & & \\
\hline Iraq (\& Afghanistan/Iraq) & $42(17.7 \%)$ & $36(22.8 \%)$ & $5(6.3 \%)$ & & \\
\hline World war & $20(8.4 \%)$ & $16(10.1 \%)$ & $4(5.1 \%)$ & & \\
\hline Vietnam & $17(7.2 \%)$ & $4(2.5 \%)$ & $13(16.5 \%)$ & & \\
\hline Author & & & & 1.9 & .398 \\
\hline Military author & $119(50.2 \%)$ & 75 (47.5\%) & $44(55.7 \%)$ & & \\
\hline Not military & $79(33.3 \%)$ & $54(34.2 \%)$ & $25(31.6 \%)$ & & \\
\hline Focus of research & & & & 5.3 & $.021^{\circ}$ \\
\hline Military nursing & $183(77.2 \%)$ & $115(72.8 \%)$ & $68(86.1 \%)$ & & \\
\hline Recommendations & $54(22.8 \%)$ & $43(27.2 \%)$ & $11(13.9 \%)$ & & \\
\hline Author collaborator & & & & 5.8 & $.015^{\circ}$ \\
\hline Military nursing & $196(82.7 \%)$ & $124(78.5 \%)$ & $72(91.1 \%)$ & & \\
\hline Multidisciplinary & $41(17.3 \%)$ & $34(21.5 \%)$ & $7(8.9 \%)$ & & \\
\hline Topic area & & & & 15.8 & $.015^{*}$ \\
\hline Clinical & $57(24.1 \%)$ & $48(30.4 \%)$ & $9(11.4 \%)$ & & \\
\hline Education & $35(14.8 \%)$ & $26(16.5 \%)$ & $9(11.4 \%)$ & & \\
\hline History & $25(10.5 \%)$ & $13(8.2 \%)$ & $12(15.2 \%$ & & \\
\hline Professional & $36(15.2 \%)$ & $20(12.7 \%)$ & $16(20.3 \%)$ & & \\
\hline Occupational & $44(18.6 \%)$ & $27(17.1 \%)$ & 17 (21.5\%) & & \\
\hline Type of research & & & & 2.9 & .905 \\
\hline Quantitative & $103(43.5 \%)$ & $68(43 \%)$ & 35 (44.3\%) & & \\
\hline Qualitative & $58(24.5 \%)$ & $37(23.4 \%)$ & $21(26.6 \%)$ & & \\
\hline Historical & $43(18.1 \%)$ & $31(19.6 \%)$ & $12(15.2 \%)$ & & \\
\hline Evaluations & $15(6.3 \%)$ & $10(6.3 \%)$ & $5(6.3 \%)$ & & \\
\hline Evidence of research process & & & & 4.6 & .203 \\
\hline Excellent & $130(54.9 \%)$ & $88(55.7 \%)$ & $42(53.2 \%)$ & & \\
\hline Acceptable & $33(13.9 \%)$ & $18(11.4 \%)$ & $15(19 \%)$ & & \\
\hline Poor & $31(13.1 \%)$ & $19(12 \%)$ & $12(15.2 \%)$ & & \\
\hline
\end{tabular}

* Significance set at $\mathrm{p}<.05$

In terms of the main focus, after the commencement of the second Gulf War and Afghanistan War there appears to be a significant increase in research making recommendations for military nursing increasing from $13.9 \%$ to $22.9 \%(p=.021)$ (Table 1).

The subject domain of military nursing research also changed and as Fig. 5 illustrates, prior to 2000 historical research predominated. From 2004 onwards there is a significant increase in clinical military nursing research and this may corresponds to the commencement of the second Gulf War and Afghanistan War.

\subsection{Type of research}

In terms of methodology, the majority of research was quantitative $(n=103)$ (Table 1$)$, with the remainder being qualitative, historical and evaluation research. The most popular data collection tool was the survey $(n=65)$ followed by document review $(n=26)$. 
The research papers were rated in terms of evidence of research process and over $50 \%$ were rated as excellent $(n=130)$ and $13 \%$ as poor $(n=31)$.

\section{Discussion}

The data presents trends in the published research field of military nursing between 1990 and 2013. An area of the findings particularly worth remarking upon is the quantity of military nursing research publications; the number of military nursing research papers included was 237.

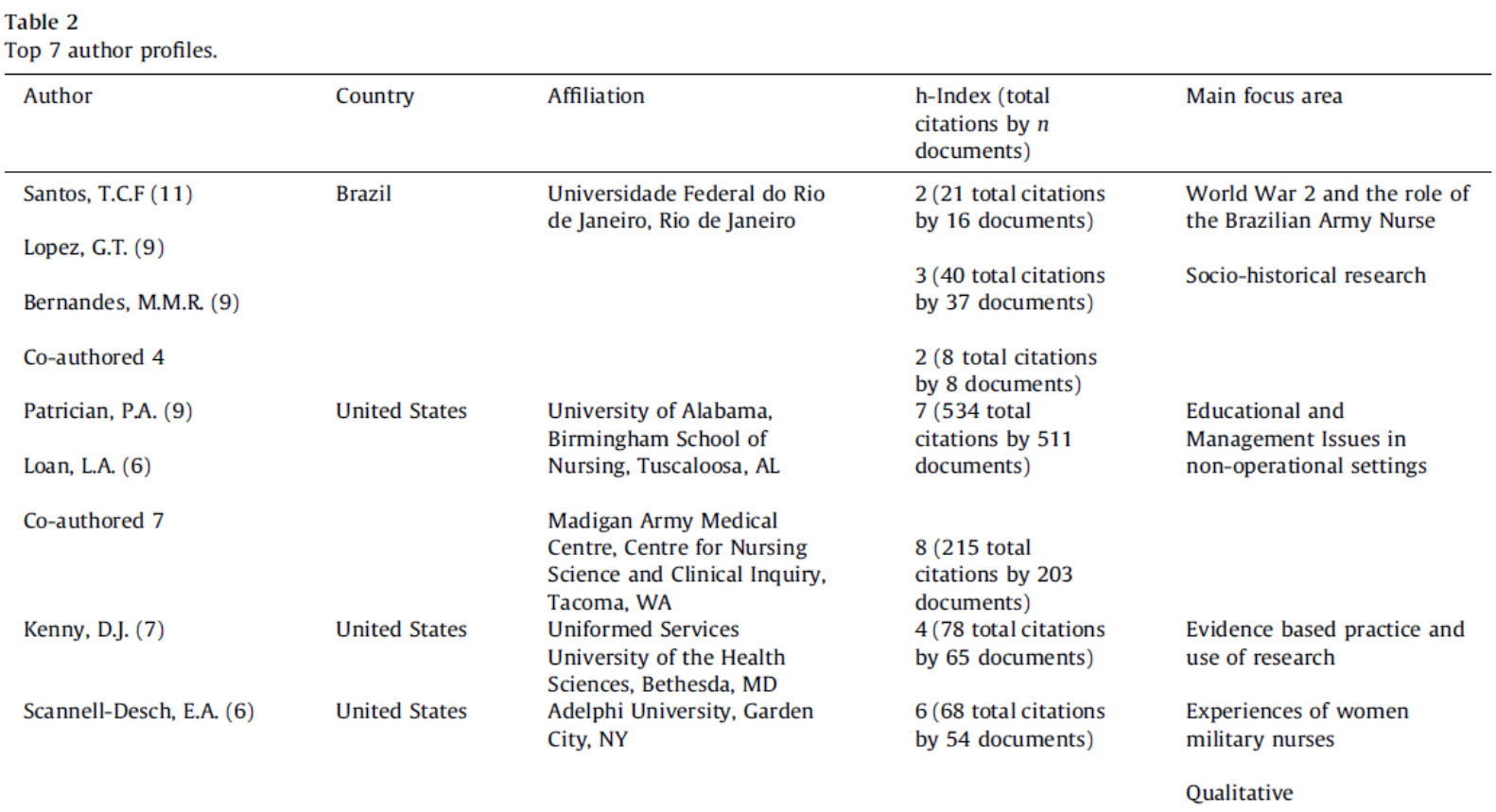

A bibliometric review of Spanish nursing research of a 10 year period (1985-1994) identified 622 papers, 62.2 papers average per year (Pardo et al., 2001). An analysis of Australian nursing research output over a five year period identified 509 papers, 101.8 average per year (Borbasi et al., 2002). Whilst these two studies are not directly comparable to this review because of the difference in time span, they do highlight that the number of military nursing research papers over the past 23 years is substantially less. In fact, the quantity of military nursing research is more closely aligned to research output in specialist areas of nursing. Between 1996 and 2006 there were 175 research studies in the field of disability nursing, an average of 15.9 papers per year (Griffiths et al., 2009). It is acknowledged that research productivity is not necessarily a marker of quality or impact, although it is interesting that the volume of military nursing research is less than other fields.

One of the key challenges facing military nurses is the issue of time, because research is often not the main job of the military nurse. Furthermore, deployments and regular posting cycles can interrupt research projects, dependent upon the level of support available (Felton et al., 1998). Undertaking longitudinal research would be problematic and supported by the fact that no longitudinal studies were identified in this review (Feider et al., 2012). 


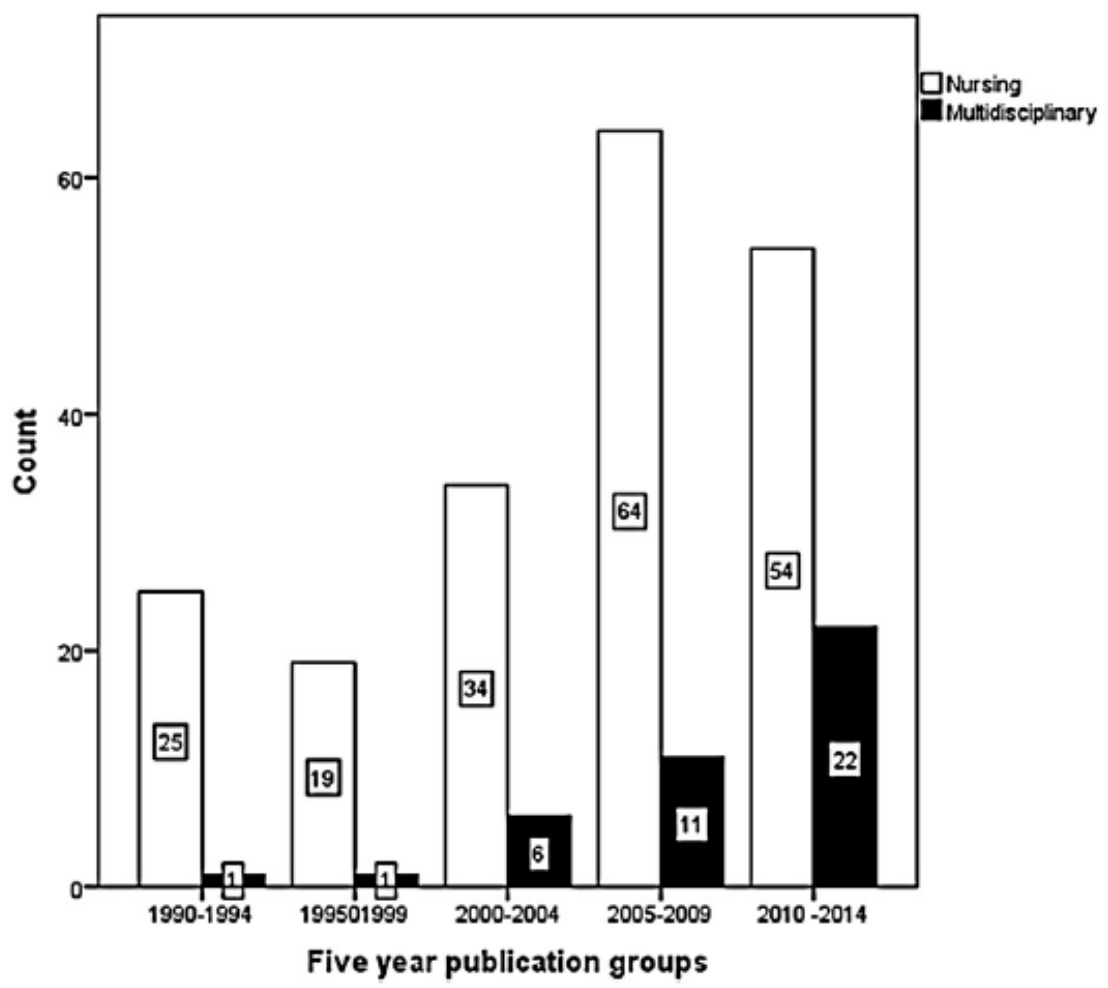

Fig. 4. Multidisciplinary and nursing research papers.

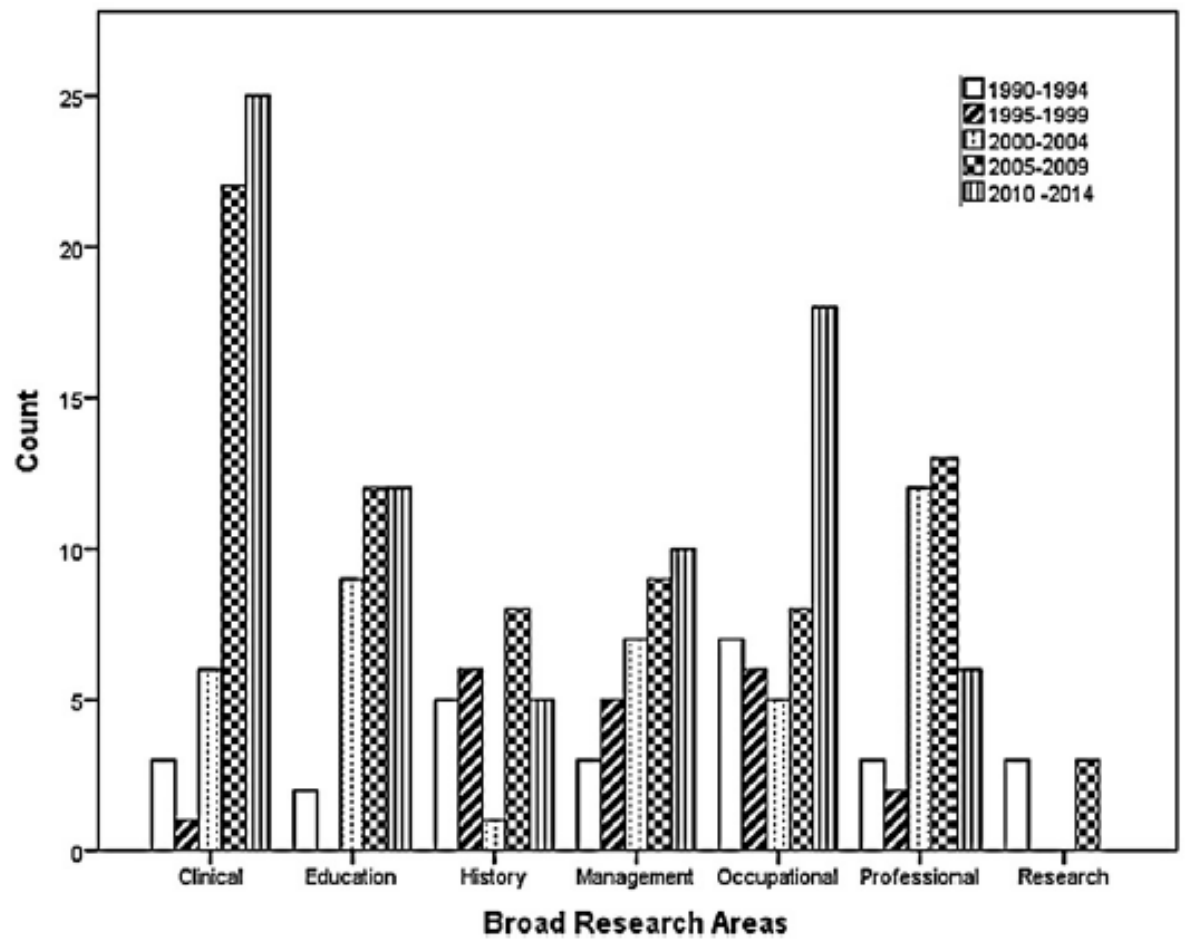

Fig. 5. Changes in subject domain focus over time. 
There are usually clearance processes for the publication of research articles and this can add a further challenge for military nurses. Above all, one of the main prohibitions to military nursing research is funding.

The majority of military nursing research emanated from the US and this is not surprising given the size and the resources available to the US military and also the number of conflicts and military operations over the past 20 years. There is a longstanding tradition of research in the US armed forces and it is argued that the Army Nursing Corps pioneered military nursing research (Kennedy, 1994). The Tri-Service Nursing Research Programme established by the US Navy, Army and Air Force in 1999, provides resources to military nursing, including a nursing frame- work to identify areas of research financial support and research supervisor support (Bridges et al., 2008; Schmelz et al., 2003). The aim of the Tri-Service Nursing Research Programme is to answer research questions that are unique to military nursing and to translate military nursing research into military nursing practice. The programme also aims to mentor future military nurse researchers which is important in developing research skills (Smith and Hazelton, 2008). The US encourages nurses to undertake a doctorate and thereby reinforces the culture of research (Feider et al., 2012).

A number of publications emanated from Brazil and appeared to be a reflection of the work of a group of researchers with a military nursing interest in nurses' experiences in the Second World War. However, as per the predominance of papers from the US, the top authors (excluding the exception from Brazil) were Patrician and Loan with h-indices of 7 and 8. Hack et al. (2010) observed that nurses with an h-index of 10-14 indicated an excellent publication record and those with an h-index of 5-9 have a 'well established' record of publications (Hack et al., 2010, p. 2546). It is not unusual that there are few prolific authors within the military nursing field. In keeping with Lokta's Law of Scientific Productivity, in any given field $60 \%$ of authors produce 1 paper and $6 \%$ produce 10 (Estabrooks et al., 2004; Lokta, 1926).

It is also of interest that the geographical dominance of military nursing research has remained with the US throughout the period 1990-2013, with Australia entering into the field from 2000 onwards and Brazil and UK from 2005 onwards. In other fields, including public health research and fields of nursing the US has also displayed dominance in research productivity (Anderson et al., 2009; Clarke et al., 2007). Of concern is that all of the papers focusing on the Gulf Wars and Afghanistan (except one by the UK) are from the US and subsequently the military nursing field reflects a skewed perspective of deployment activities to this region. International collaboration was not identified and this further reflects the immaturity of the military nursing field and several authors advocate international collaboration as a method of raising bibliometric profile (Estabrooks et al., 2004; Smith and Hazelton, 2008). The median impact factor was 0.88 and this is similar to other nursing fields where the majority of papers are published in journals with either no impact factor or an impact factor less than two (Johnstone, 2007; Smith and Hazelton, 2008). This is an area of focus for the development of the military nursing field and it is hoped that coupled with the significant increase in the number of papers published per year and the shift in focus towards clinical research that journals will be more likely to have an appetite for military nursing papers. Furthermore the mean 
references per paper showed a significant increase in the period following 2003 (19.8-25.4) and this quantity is similar to other fields of nursing (Estabrooks et al., 2004; Pardo et al., 2001).

The shift in the focus of research also deserves remarking upon. Prior to the commencement of the second Gulf War and Afghanistan War in the early 200os, the focus of research was occupational, professional and historical and post commencement the focus shifted to include clinical and occupational research as areas of dominance. This shift towards clinical research is to be expected given the length of these wars and the evolving character of ballistic injuries that required the development of new and refined techniques, particularly in the fields of nursing and medicine. Within the clinical research, papers were focused on a variety of topics including trauma, mental health and women's health. There was little research published on military nursing in relation to humanitarian aid and this may be a consequence of the unpredictability of humanitarian aid missions and therefore difficulty in researching this topic contemporaneously.

The extent to which the knowledge within a field is open or closed to transfer to other disciplines, has been identified as a bibliometric marker; this is established by identifying the presence of disciplinary sources of references (Estabrooks et al., 2004). In the field of military nursing there was a marked increase in papers that make recommendations for military nursing and there is an increasing quantity of multidisciplinary research. In keeping with the concept of knowledge transfer, these factors indicate the increasing potential to translate knowledge gained from nursing research to other health professions. Examples include helicopter evacuation services patient outcome and projects based in mental health (Brewer and Ryan-Wenger, 2009; Ebbs and Timmons, 2008; Finnegan and Finnegan, 2007; Finnegan et al., 2013; Gibbons et al., 2011; Kee et al., 2005; Lairet et al., 2013). This shift also acknowledges the collaborative nature of military healthcare and as a marker of bibliometric profile it signals that the field of military nursing is open to transfer to other disciplines (Estabrooks et al., 2004).

\section{Limitations}

The review has some limitations. In presenting the results of this review, though every effort was made to identify relevant papers, the challenges around identifying exactly what would be defined as military nursing and the use of keywords for military nursing may have led to some papers not being identified in the searches. Whilst each of the papers was reviewed by both authors, a consensus of two may have introduced bias and this may have been reduced had the research team been larger. Furthermore, identification of relevance of multidisciplinary papers to military nursing was open to different interpretations and might have introduced classification bias. This was resolved as far as possible, by examining whether the article was focused on military nursing practice and/or held recommendations for military nursing practice such as identifying risk factors for mental, physical, and functional health in war veterans (King et al., 2008).

The papers of a lesser methodological clarity, those rated as 1 (poor), were often difficult to interpret with limited information of method, analysis of data and 
presentation of results and therefore difficult to classify. These issues highlight the importance of clearly identifying research papers with accurate key terms and articulating the method and data collection.

A second limitation relates to the access to full research papers. Where the full paper was not available $(n=37)$ the abstract was used to classify the article. Where the papers were written in another language and were not formally translated $(n=23)$, only the abstracts of these papers were written in English and this was used to classify the papers. Using only the abstract to classify some of the researchers papers has the potential to alter the interpretation of the military nursing field and the quality of the research methodology. Despite the limitations of this review, it does provide initial insight into a topic area that has been previously unexplored using bibliometrics.

\section{Conclusion}

The bibliometric review presents trends in the published research field of military nursing between 1990 and 2013. The military nursing field is dominated by the US and as such this provides a skewed perspective to the field of military nursing internationally. As it stands the field appears underdeveloped, although there are signs of increasing momentum in terms of the quantity of papers published, references per paper, the impact factor of journals and the increase in multidisciplinary research. Recommendations to improve the bibliometric profile of military nursing include targeting higher impact journals, having clear identifiable keywords and of critical importance is for military nursing forces to devise research strategies that include international and multidisciplinary collaboration. The field of military nursing holds unique challenges and until the lessons learned are researched and documented they will remain silent to the global field of nursing research and what an enormous loss that would be.

Conflict of interest: No conflict of interest.

Funding: No funding.

Ethical approval: Not required for bibliometric review. 


\section{References}

Agazio, J., 2010. Army nursing practice challenges in humanitarian and wartime missions. Int. J. Nurs. Pract. 16, 166-175.

Anderson, C.A., Keenan, G., Jones, J., 2009. Using bibliometrics to support your selection of a nursing terminology set. Comput. Inform. Nurs. 27 (2), 82-90.

Aronson, N.E., Sanders, J.W., Moran, K.A., 2006. In harm's way: infections in deployed American military forces. Clin. Infect. Dis. 43, 1045-1051.

Borbasi, S., Hawes, C., Wilkes, L., Stewart, M., May, D., 2002. Measuring the outputs of Australian nursing research published 1995-2000. J. Adv. Nurs. 38 (5), 489-497.

Brewer, T.L., Ryan-Wenger, N.A., 2009. Critical Care Air Transport Team (CCATT) nurses' deployed experience. Mil. Med. 174 (5), 508-514.

Bridges, E., 2010. Facilitation of evidence-based nursing practice during military operations. Nurs. Res. 59 (1S), S75-S79.

Bridges, E.J., Schmelz, J., Kelley, P.W., 2008. Military nursing research: translation to disaster response and day-to-day critical care nursing. Crit. Care Nurs. Clin. North Am. 20 (1), 121-131, http://dx.doi.org/ 10.1016/j.ccell.2007.10.011, viii.

Clarke, A., Gatineau, M., Grimaud, O., Royer-Devaux, S., Wyn-Roberts, N., Le Bis, I., Lewison, G., 2007. A bibliometric overview of public health research in Europe. Eur. J. Public Health 17 (1), 43-49.

Eastridge, B.J., Jenkins, D., Flaherty, S., Schiller, H., Holcomb, J.B., 2006. Trauma system development in a theater of war: experiences from Operation Iraqi Freedom and Operation Enduring Freedom. J. Trauma 61, 1366-1372.

Ebbs, N.L., Timmons, S., 2008. Inter-professional working in the RAF Critical Care Air Support Team (CCAST). Intens. Care Crit. Care Nurs. 24 (1), 51-58, http://dx.doi.org/10.1016/j.iccn.2007.06.003.

Estabrooks, C.A., Winther, C., Derksen, L., 2004. Mapping the field a bibliometric analysis of the research utilisation literature in nursing. Nurs. Res. 53 (5), 293-303.

Feider, L.L., Platterborze, L.S., McLinton, A.R., Garner, B.K., 2012. Combat casualty care nursing research and the joint combat casualty research team. Army Med. Dep. J. 64-71.

Felton, G., McCorkle, M.R., Redman, B., 1998. The coming of age of military nursing research. J. Prof. Nurs. 14 (2), 85-91.

Finnegan, A., Finnegan, S., 2007. Assessing the effectiveness of the British Army's mental health service. Br. J. Nurs. 16 (12), 725-730.

Finnegan, A., Finnegan, S., McGee, P., Srinivasan, M., Simpson, R., 2013. Predisposing factors leading to depression in the British Army. Br. J. Nurs. 19 (21), 1355-1362, http://dx.doi.org/10.12968/bjon.2010.19.21.80000.

Gibbons, S.W., Hickling, E.J., Watts, D.D., 2011. Combat stressors and posttraumatic stress in deployed military healthcare professionals: an 
integrative review. J. Adv. Nurs. 3-21, http://dx.doi.org/10.1111/j. 1365-2648.2011.

Griffiths, P., Bennett, J., Smith, E., 2009. The size, extent and nature of the learning disability nursing research base: a systematic scoping review. Int. J. Nurs. Stud. 46, 490-507.

Hack, T.F., Crooks, D., Plohman, J., Kepron, E., 2010. Research citation analysis of nursing academics in Canada: idenifying success indicators. J. Adv. Nurs. 66, 2542-2546.

Hettiaratchy, S., Tai, N., Mahoney, P., Hodgetts, T., 2010. UK's NHS Trauma Systems: lessons from military experience. Lancet 376, 149.

Hodgetts, T.J., Mahoney, P.F., Kirman, E., 2007. Damage control Resusciation. J. R. Army Med. Corps 153, 299-300.

Johnstone, M.J., 2007. Journal impact factors. Int. Nurs. Rev. 54, 35-40. Kee, C.C., Foley, B.J., Dudley, W.N., Jennings, B.M., Minick, P., Harvey, S.S., 2005. Nursing structure, processes, and patient outcomes in army medical centers. West. J. Nurs. Res. 27 (8), 1040-1058.

Kennedy, T.E., 1994. The evolution of nursing research in the Army Nurse Corps. Mil. Med. 159 (11), 680-683.

King, L.A., King, D.W., Bolton, E.E., Knight, J.A., Vogt, D.S., 2008. Risk factors for mental, physical, and functional health in Gulf War veterans. J. Rehab. Res. Dev. 45 (3), 395-407.

Lairet, J., King, J., Vojta, L., Beninati, W., 2013. Short-term outcomes of US air force Critical Care Air Transport Team (CCATT) Patients evaluated from a combat setting. Prehosp. Emerg. Care 17, 486-490.

Leon, G.R., Ben Porath, Y.S., Hjemboe, S., 1990. Coping patterns and current functioning in a group of vietnam and vietname-era nurses.

J. Soc. Clin. Psychol. 9 (3), 334-353.

Lievrouw, L.A., 1989. The invisible college reconsidered: bibliometrics and the development of scientific communication theory. Commun. Res. 16 (5), 615-628.

Lokta, A.J., 1926. Statistics: the frequency distribution of scientific productivity. J. Washington Acad. Sci. 16 (12), 317-323.

Mabry, R.L., Holcomb, J.B., Baker, A.M., Cloonan, C.C., Uhorchak, J.M., Perkins, D.E., Hagmann, J.H., 2000. United States Army Rangers in Somalia: an analysis of combat casualties on an urban battlefield. J. Trauma 49 (3), 515-529.

Nightingale, F., 1859. Notes on Nursing. Duckworth.

Orman, J.A., Eastridge, B.J., Baer, D.G., Gerhardt, R.T., Rasmussen, T.E., Blackbourne, L.H., 2012. Impact of 10 years of war on combat casualty care research: a citation analysis. J. Trauma Acute Care Surg. 73 (6 (Suppl. 5)), S403-S408, http://dx.doi.org/10.1097/TA.obo13e3182754834.

Pardo, C., Reolid, M., Delicado, M.V., Mallebrera, E., Garcia-Meseguer, M.J., 2001. Nursing research in Spain: bibliometrics of references of research papers in the decade 1985-1994. Methodol. Issues Nurs. Res. 35 (6), 933-943. 
Patrician, P.A., 2013. Hospital nursing units in the USA: government ownership, Magnet designation, unit population age group and higher skill mix are associated with lower nursing turnover. Evid. Based Nurs. 16 (4), 119-120, http://dx.doi.org/10.1136/eb-2012-101114.

Schmelz, J.O., Bridges, E.J., Duong, D.N., Ley, C., 2003. Care of the critically ill patient in a military unique environment: a program of research. Crit. Care Nurs. Clin. North Am. 15, 171-181.

Smith, D.R., Hazelton, M., 2008. Bibliometrics, citation indexing, and the journals of nursing. Nurs. Health Sci. 10, 260-265.

Thompson, R.D., Watson, R., 2010. Guest editorial: h-indices and the performance of professors of nursing in the UK. J. Clin. Nurs. 19 (21), 2957-2958.

Wildridge, D.J., Hodgetts, T.J., Mahoney, P.F., 2012. The Joint Theatre Clinical Case Conference (JTCCC); clinical governance in action. J. R. Army Med. Corps 156, 79-83. 